\title{
Eosinophil recruitment and activation: the role of lipid mediators
}

\author{
Tatiana Luna-Gomes ${ }^{1}$, Patrícia T. Bozza ${ }^{2}$ and Christianne Bandeira-Melo ${ }^{1}$ * \\ ${ }^{1}$ Instituto de Biofísica Carlos Chagas Filho, Universidade Federal do Rio de Janeiro, Rio de Janeiro, Brazil \\ ${ }_{2}^{2}$ Instituto Oswaldo Cruz, Rio de Janeiro, Brazil
}

Edited by:

Amr El-Shazly, Liege University

Hospital, Belgium

Reviewed by:

Amr El-Shazly, Liege University Hospital, Belgium

Mustapha Zeddou, Laboratory of

Rheumatology GIGA-Research

Center, University of Liège, Belgium

*Correspondence:

Patrícia T. Bozza, Laboratório de Imunofarmacologia, Instituto Oswaldo

Cruz, Fundação Oswaldo Cruz, Av.

Brasil 4365, 21045-900 Rio de

Janeiro, Brazil.

e-mail:pbozza@ioc.fiocruz.br;

Christianne Bandeira-Melo,

Laboratório de Inflamação, Instituto

de Biofísica Carlos Chagas Filho,

Universidade Federal do Rio de

Janeiro, CCS, Room C1-024, Av.

Carlos Chagas Filho 373, Illha do

Fundão, 21941-902 Rio de Janeiro,

Brazil.

e-mail:cbmelo@biof.ufri.br
Eosinophils are effector cells that migrate toward several mediators released at inflammatory sites to perform their multiple functions. The mechanisms driving eosinophil selective accumulation in sites of allergic inflammation are well-established and involve several steps controlled by adhesion molecules, priming agents, chemotactic, and surviving factors. Even though the majority of studies focused on role of protein mediators like IL-5 and eotaxins, lipid mediators also participate in eosinophil recruitment and activation. Among the lipid mediators with distinguish eosinophil recruitment and activation capabilities are platelet activating factor and the eicosanoids, including leukotriene $B_{4}$, cysteinyl leukotrienes, and prostaglandin $D_{2}$. In this review, we focused on the role of these four lipid mediators in eosinophil recruitment and activation, since they are recognized as key mediators of eosinophilic inflammatory responses.

Keywords: eosinophil, chemotaxis, lipid mediators, prostaglandins, leukotrienes
Eosinophils are nowadays considered as multifunctional cells that have long been associated with allergy and parasitic infections. They are immunomodulatory cells that participate both in innate and adaptive immune response via expression of various receptors and secretion of a variety of mediators. To perform their functional activities, first eosinophils must migrate to sites of inflammatory reaction. Over the last years, a number of mediators and receptors involved in the regulation of eosinophil recruitment have been identified. Besides adhesion molecules and cytokines, eosinophil mobilization is mostly coordinated by a broad range of bioactive mediators known as chemokines. These molecules are an increasing family of small proteins with common structural motifs that via activation of their specific receptors play an important role not only in selective recruitment of eosinophils but also in subsequent eosinophil activation in sites of eosinophilic inflammation. Even though the main efforts in this research area are directed toward peptidic mediators, like chemokines, a growing body of data has unveiled key roles of lipid mediators in regulating eosinophil migration and activation. Among bioactive lipids, eicosanoids are a large family of distinctive mediators derived from arachidonic acid (AA) metabolization regularly found at high levels in inflammatory sites. Displaying from pro- to anti-inflammatory, pro-resolution, and even immunomodulatory functions, these molecules are key mediators in the pathogenesis of diverse inflammatory diseases, such as asthma, infection, and cancer. This review will first explore the role of some of the most well-studied lipid mediators on eosinophil migration. Then, it will summarize the impact of a varied of these mediators on eosinophil activation, focusing on eosinophil secretory function of leukotriene $\mathrm{C}_{4}\left(\mathrm{LTC}_{4}\right)$ synthesis/release.

\section{HOW DO LIPID MEDIATORS IMPACT EOSINOPHIL MIGRATION?}

Eosinophilia is a classical feature of allergic inflammatory responses, therefore regulation of eosinophil migration to the inflammatory focus is a critical stage in the processes of chronic inflammation that affect, for instance, asthmatic airways. Eosinophil recruitment into the tissues after immune or chemical stimuli requires the production of chemoattractants by several cells such as macrophages, mast cells, or lymphocytes. Briefly, local increase in the secretion of eosinophilotactic molecules, leads to eosinophil adhesion to the endothelium through interaction with selectins expressed on the vascular endothelium followed by firm adhesion through interaction with integrins. Subsequent transmigration through the endothelial cell monolayer is followed by chemotaxis in the tissue, a process known to be largely controlled by chemokines such eotaxina-1, 2, 3, and RANTES and their specific receptors, especially CCR3 (Simson and Foster, 2000). However, both in vivo and in vitro, eosinophils 
also migrate toward different factors distinct from chemokines such as C5a (Klebanoff et al., 1977), interleukin-5 (IL-5; Wang et al., 1989), granulocyte-macrophage colony-stimulating factor (GM-CSF; Secor et al., 1990), and lipid mediators. Indeed, AA metabolites as leukotrienes and prostaglandins (PGs), as well as, platelet activating factor (PAF) are considered major players in the pathogenesis of asthma and other forms of allergic inflammation, in part because they control eosinophil influx and activation.

Within a variety of cell types, phospholipase $\mathrm{A}_{2}$-driven AA mobilization followed by the oxidative metabolism of free AA mediated by either two cyclooxygenases (COX, PG H synthase) or a family of lipoxygenase (LO) enzymes culminate with the generation of bioactive lipid mediators with roles in eosinophilic inflammation. Specifically concerning those with ability to elicit eosinophil recruitment, newly synthesized lipid mediators may comprise:

\section{LEUKOTRIENE $\mathrm{B}_{4}$}

Leukotriene $\mathrm{B}_{4}\left(\mathrm{LTB}_{4}\right)$ is a lipid mediator with potent chemoattractant properties that is rapidly generated from activated innate immune cells such as neutrophils, macrophages, and mast cells. Elevated levels of $\mathrm{LTB}_{4}$ have been reported in various allergic diseases and these levels have been related to disease activity and eosinophilia (O'Driscoll et al., 1984; Wardlaw et al., 1989; Shindo et al., 1993). LTB $_{4}$ can bind to two highly conserved G protein-coupled receptors (GPCRs), $\mathrm{LTB}_{4}$ receptor 1 (BLT1) and the considered low-affinity BLT2 (Toda et al., 2002; Yokomizo, 2011). LTB $_{4}$ serves as a potent chemoattractant through ligation of BLT1 on target cells. Expression and function of $\mathrm{LTB}_{4}$ receptors on eosinophils remained for long time controversial, in part because $\mathrm{LTB}_{4}$-driven activity seemed to have some selectivity toward neutrophils. However, while strong demonstration of BLT1 expression in human eosinophils is still pending, functional assays using $\mathrm{LTB}_{4}$ as agonist and specific BLT1 antagonists have provided evidences of expression of active BLT1 on human eosinophils. For instance, it has been shown a BLT1-driven $\mathrm{LTB}_{4}$ ability to trigger calcium influx in human eosinophils (Murray et al., 2003a). On the other hand, murine (m)BLTR was cloned while searching for novel chemoattractant receptors in murine eosinophils and demonstrated that it encodes a functional receptor for $\mathrm{LTB}_{4}$ which are able to trigger chemotaxis of mouse eosinophils (Figure 1, left panel; Spada et al., 1997; Huang et al., 1998). Reinforcing both in vitro data and in vivo assays with BLT1 antagonists, in vivo studies using BLT1-deficient mice have confirmed that ligation of BLT1 by $\mathrm{LTB}_{4}$ is a key event for recruitment of eosinophils (Tager et al., 2000) However, it is noteworthy that while mouse eosinophils may generate only negligible amounts of $\mathrm{LTB}_{4}$, human eosinophils are not $\mathrm{LTB}_{4}$ producers, representing major cellular sources of cysteinyl LTs (Weller et al., 1983). Based on the prominent eosinophil feature of recurrently depend on autocrine/paracrine stimulation to regulate their own functions, it seemd to be potentially more important the role of cysteinyl LTs in inducing eosinophilic responses, including autocrine/paracrine roles in induction of eosinophil chemotaxis and activation.

\section{CYSTEINYL LEUKOTRIENES}

Leukotriene $\mathrm{C}_{4}$ and its extracellular derivatives $\mathrm{LTD}_{4}$ and $\mathrm{LTE}_{4}$ have many well recognized actions as mediators of allergic response, causing bronchoconstriction, mucous hypersecretion, increased microvascular permeability, and bronchial hyperresponsiveness. Additional but not as well-established effect is the ability of cysteinyl LTs to control eosinophil activities, including those related to tissue infiltration. Involvement of cysteinyl LTs in eosinophil influx is an in vivo phenomenon which was firstly demonstrated in guinea-pigs (Chan et al., 1990), but also observed in human (Laitinen et al., 1993) and reinforced by the anti-allergic effects of CysLT1 antagonists which, in addition to inhibiting allergic symptoms, also inhibit eosinophil recruitment during airway allergic inflammation (Peters-Golden, 2008). Even though cysteinyl LTs display negligible eosinophilotactic activity in vitro (Figure 1, left panel; Fregonese et al., 2002), cysteinyl LTs contribute to several mechanisms involved in mouting tissue

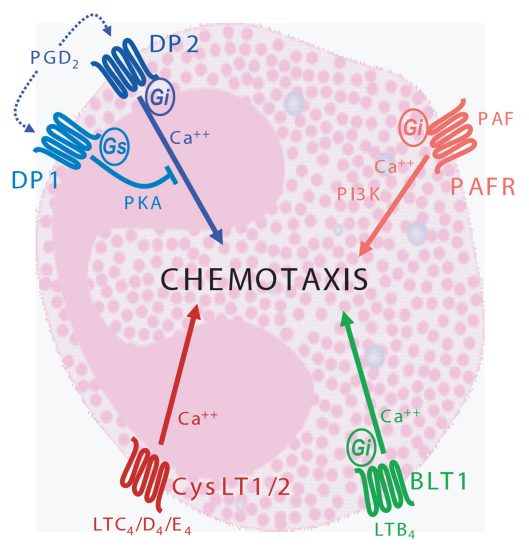

FIGURE 1 | Schematic mechanisms of LTB $_{4^{-}}$, LTC $_{4}{ }^{-}$, PAF-, or $\mathbf{P G D}_{2}$-induced eosinophil chemotaxis and $\mathbf{L T C}_{\mathbf{4}}$ synthesis. Left eosinophil scheme displays the ability of the four lipid mediators to trigger eosinophil chemotaxis by activating receptor-mediated distinct intracellular signaling. In contrast, the right eosinophil scheme shows that only $\mathrm{PGD}_{2}$ and PAF are

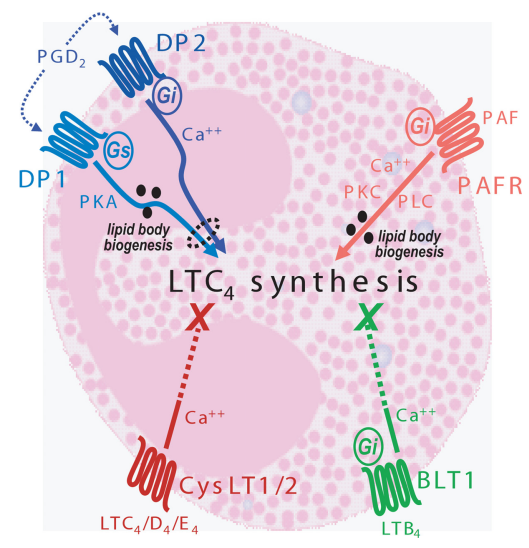

capable of activating $\mathrm{LTC}_{4}$ synthesizing machinery, yet again by eliciting distinct signaling, but both by a lipid body-dependent mechanism. The right scheme also illustrates that both leukotrienes $\mathrm{LTB}_{4}$ and $\mathrm{LTC}_{4}$, even thought activate their specific receptors in eosinophils (see left panel), failed to trigger lipid body biogenesis or $\mathrm{LTC}_{4}$ synthesis. 
eosinophilia, since: (i) cysteinyl receptor CysLT1 appears to play a role in eosinophilopoeisis, inasmuch as CysLT1 antagonism in vivo limits IL-5-responsive eosinophil differentiation and maturation (Saito et al., 2004); (ii) cysteinyl LTs are able to significantly upregulate adhesion molecules, such as Mac-1 expression (Fregonese et al., 2002; Saito et al., 2004); (iii) direct administration of $\mathrm{LTC}_{4}$ induce a rapid and significant reduction in leukocyte rolling velocity, further increasing cell adherence odds (Kanwar et al., 1995); (iv) cysteinyl LTs induce RANTES production from isolated lung cells, which in turn might cause RANTES-driven migration of eosinophils into airways (Kawano et al., 2003).

\section{PLATELET ACTIVATING FACTOR}

One major chemoattractant for eosinophils is the etherlinked phospholipid, PAF. PAF (1-O-alkyl-2-acetyl-sn-glycero-3phosphocholine) is another potent lipid mediator synthesized by a range of cell types, including monocytes/macrophages, mast cells, platelets, neutrophils, endothelial cells as well as eosinophils. PAF is capable of eliciting both chemokinesis and chemotaxis in vitro and triggering eosinophil influx and accumulation in vivo (Wardlaw et al., 1986; Kimani et al., 1988; Martins et al., 1989; Kato et al., 2004). Acting via a single class of identified receptor - named PAFR - a seven-trans-membrane G proteincoupled receptor, PAF evokes not only migration-related activities but also a variety of eosinophilic functional responses (Grigg, 2012). Of note, while it became more and more clear that human and mouse eosinophils shared profound dissimilarities (Lee etal., 2012), both express functional active PAFR which mediates eosinophilotactic activity of PAF in human and mouse cells by a pertussis toxin (PTX)-sensitive manner. Several studies have tryed to characterize the signaling pathways involved in PAFinduced eosinophil chemotaxis, and although still controversial, it is now recognized that eosinophilotactic responses triggered by PAF depend on activation of mitogen-activated protein (MAP) kinases, while upstream signaling events are regulated by activation of phosphoinositide 3-kinase (PI3K; Figure 1, left panel; Dent et al., 2000; Miike et al., 2000). Indeed, these findings are in agreement with the demonstration that PI3K inhibitors suppress PAF-mediated tissue eosinophilia in diseases such as asthma (Mishra et al., 2005).

\section{PROSTAGLANDIN $\mathrm{D}_{\mathbf{2}}$}

Prostaglandin $\mathrm{D}_{2}$ has emerged as a key mediator of allergic diseases such as asthma (Matsuoka et al., 2000), in part due to its now wellcharacterized ability to promote potent eosinophil chemotaxis and activation (Powell, 2003). $\mathrm{PGD}_{2}$-driven cellular functions are all mediated by high-affinity interaction with two receptors, namely D prostanoid receptor $1\left(\mathrm{DP}_{1}\right)$ and chemoattractant receptorhomologous molecule expressed on Thelper type 2 cell (Th2) cells (CRTh2, also known as $\mathrm{DP}_{2}$ ). Whilst $\mathrm{DP}_{1}$ is coupled to Gas protein and signals through elevation of intracellular levels of cyclic adenosine monophosphate (cAMP), $\mathrm{DP}_{2}$ is coupled to Gai and its activation leads to elevation of intracellular calcium, reduction in cAMP (Sawyer et al., 2002) and downstream activation of PI3K (Xue et al., 2007). Eosinophils co-express both the classic $\mathrm{DP}_{1}$ receptors coupled to adenylyl cyclase, as well as, PTX-sensitive $\mathrm{DP}_{2}$ (Monneret et al., 2001).
Prostaglandin $\mathrm{D}_{2}$-mediated eosinophilotactic effect is due to direct activation of the $\mathrm{DP}_{2}$ receptor expressed on eosinophil surface (Monneret et al., 2003). Several pharmacological studies show the involvement of $\mathrm{DP}_{2}$ in the establishment of eosinophilia in models of allergic inflammation. For instance, intratracheal injection of $\mathrm{PGD}_{2}$ or selective $\mathrm{DP}_{2}$ agonist induced eosinophilia in rats, whereas the use of selective $\mathrm{DP}_{1}$ agonist failed to trigger eosinophil accumulation (Emery et al., 1989). Likewise, intratracheal administration of $\mathrm{DP}_{2}$ agonist or $\mathrm{PGD}_{2}$ induced specific airway eosinophilia in mice previously exposed to the allergen or IL-5 (Shiraishi et al., 2005). $\mathrm{DP}_{2}$ antagonist abrogated the $\mathrm{PGD}_{2}$ induced mobilization of eosinophils from the bone marrow of the guinea-pig confirming a crucial role of $\mathrm{DP}_{2}$ in this response (Royer et al., 2008). A specific $\mathrm{DP}_{2}$ agonist not only increased eosinophil recruitment at inflammatory sites but also the pathology in two in vivo models of allergic inflammation: atopic dermatitis and allergic asthma (Spik et al., 2005). Concurring, selective $\mathrm{DP}_{2}$, but not $\mathrm{DP}_{1}$ antagonists were capable to inhibit eosinophil accumulation in a model of $\mathrm{PGD}_{2}$-induced eosinophilic pleurisy (Mesquita-Santos et al., 2011). In vitro, $\mathrm{PGD}_{2}$ is able to promote additional migration-related activities, such as increased expression of cell adhesion molecules CD11b and L-selectin, calcium mobilization, actin polymerization, chemokinesis and a rapid change in eosinophil morphology (Gervais et al., 2001; Monneret et al., 2001). Of note and as illustrated in Figure 1 (left panel), these and other in vitro studies have collectively unveiled that $\mathrm{PGD}_{2}$-driven eosinophil chemotaxis may be determined by a balance between opposing downstream signaling pathways: cAMPdependent inhibitory $\mathrm{DP}_{1}$ versus prevailing stimulatory $\mathrm{DP}_{2}$ intracellular effects (Monneret et al., 2003; Ulven and Kostenis, 2006; Sandig et al., 2007). However, further studies appears to be still needed to fully explain $\mathrm{PGD}_{2}$ mechanisms of actions, since recently it has been shown that $\mathrm{DP}_{1}$ and $\mathrm{DP}_{2}$ may form heteromers representing a distinct functional signaling unit on eosinophil membrane with non-changed ligand-binding features (Sedej et al., 2012). In fact, these are not the first findings showing the ability of $\mathrm{DP}_{1}$ receptors to amplify the biological response to $\mathrm{DP}_{2}$ activation in eosinophils (Mesquita-Santos et al., 2011) a process that, although may not play roles in eosinophil migration, it appears to be critical to $\mathrm{PGD}_{2}$-induced eosinophil activation (see below).

\section{DO LIPID MEDIATORS ACTIVATE EOSINOPHIL EFFECTOR FUNCTIONS?}

At the sites of eosinophilic accumulation, through their ability to secrete a range of cytokines, basic proteins, reactive oxygen species as well as lipid mediators, eosinophils contribute to the physiopathology of a growing list of conditions including classical eosinophil-related diseases such as bronchial asthma, novel and quite surprising pathologies such as cancer, multiple sclerosis, Duchene muscular dystrophy as well as physiological process such as mammary development (Jacobsen et al., 2012). While the regulation of eosinophil migration to the inflammatory focus is a critical stage in eosinophilic pathologies, understanding the mechanisms by which eosinophil activation is stimulated and its consequences appear to be even more important in defining potential targets for therapeutic interventions, since the specific stimulatory molecules, its receptors and signaling pathways involved in 
eosinophil activation and subsequent mediator secretion may each be susceptible to inhibition. Indeed among different parameters of eosinophil activation, eosinophil secretory activity may represent the most attractive target to development of therapeutical maneuvers. Upon activation, eosinophil may engage both in secretion of pre-formed granule-stored contents, including eosinophil specific toxic proteins, enzymes, cytokines, chemokines, and other bioactive mediators, as well as de novo synthesized/released molecules including oxygen free radicals but prominently lipidic AA-derived mediators. The unique eosinophil pattern of oxidative metabolism of AA generates a specific array of eicosanoids. Eosinophils can synthesize lipoxin $\mathrm{A}_{4}\left(\mathrm{LXA}_{4}\right)$ and the aptly named after eosinophils, eoxin $\mathrm{C}_{4}\left(\mathrm{EXC}_{4}\right)$, besides the prostanoids thromboxane $\mathrm{B}_{2}\left(\mathrm{TXB}_{2}\right), \mathrm{PGE}_{2}$ and the recently identified $\mathrm{PGD}_{2}$. However, when properly stimulated, eosinophils prominently synthesize cysteinyl LTs. Of note, eosinophils are a major cellular source of cysteinyl LTs and have been identified as the principal LTC $_{4}$ synthase expressing cells in bronchial mucosal biopsies of asthmatic subjects (Bandeira-Melo and Weller, 2003). Hence, much interest in understanding the regulation of eicosanoid formation in eosinophils has focused on the mechanisms that regulate eosinophil cysteinyl LTs formation and release. Briefly, free AA can be metabolized within eosinophils by $5-\mathrm{LO}$, which is the limiting enzyme of leukotriene synthesis. 5-LO catalyzes a two-step reaction. First, 5-LO targets free AA in concert with the 5-LOactivating protein (FLAP) to insert one oxygen molecule into the 5 position of AA to form 5S-hydroperoxyeicosatetraenoic acid (HPETE), then transforms 5-HPETE into an unstable allylic epoxide, named $\mathrm{LTA}_{4}$. The subsequent metabolism of $\mathrm{LTA}_{4}$ also differs between leukocytes. In neutrophils, for instance, $\mathrm{LTA}_{4}$ hydrolase enzymatically hydrolyses 5-LO-metabolite $\mathrm{LTA}_{4}$ to $\mathrm{LTB}_{4}$. In contrast within human eosinophils, which do not express $\mathrm{LTA}_{4}$ hydrolase and therefore are incapable of $\mathrm{LTB}_{4}$ synthesis, a specific glutathione S-transferase, named $\mathrm{LTC}_{4}$ synthase $\left(\mathrm{LTC}_{4} \mathrm{~S}\right)$, catalyzes the adduction of reduced glutathione (a tripeptide composed by glutamic acid, glycine, and cysteine) to $\mathrm{LTA}_{4}$ to form $\mathrm{LTC}_{4}$. After energy-dependent export, $\mathrm{LTC}_{4}$ is converted to $\mathrm{LTD}_{4}$ and $\mathrm{LTE}_{4}$ through sequential enzymatic removal of the glutamic acid by $\gamma$-glutamyl transpeptidases and then the glycine by dipeptidases. Therefore, because these LTs share a cysteine, $\mathrm{LTC}_{4}$ and its extracellular derivatives $\mathrm{LTD}_{4}$ and $\mathrm{LTE}_{4}$ are collectively called cysteinyl LTs.

Similar to how we presented the roles of lipid mediators in inducing eosinophil migration, here we will also summarize some activating roles of $\mathrm{LTB}_{4}$, cysteinyl LTs, PAF and $\mathrm{PGD}_{2}$, but we will give special emphasis to a prototype parameter of eosinophil activation: eosinophil ability to activate LTC $_{4}$ synthesizing machinery.

\section{LEUKOTRIENE $B_{4}$}

Even though $\mathrm{LTB}_{4}$ receptors have been indirectly and directly found to be expressed on human and murine eosinophils, respectively, there are not many successful studies reporting $\mathrm{LTB}_{4}$-driven eosinophil activation. Mainly using as cell model guinea-pig eosinophils, it has been shown that $\mathrm{LTB}_{4}$ was capable of stimulating eosinophil recruitment, release of AA, homotypic eosinophil aggregation, as well as, rapid and transient activation of the
NADPH oxidase (Faccioli et al., 1991; Lindsay and Giembycz, 1997; Teixeira et al., 1999). Of note, the intracellular mechanisms that mediate $\mathrm{LTB}_{4}$-induced NADPH oxidase activation involve mediation by lyn kinase, PKC, and PLA 2 , but occurs essentially independently of changes in the intracellular calcium, phospholipase D, PI3K, and ERK1/2 (Perkins et al., 1995; Lindsay et al., 1998a,b; Lynch et al., 1999) Specifically regarding induction of LTC $_{4}$ synthesizing function, stimulation of human eosinophils with $\mathrm{LTB}_{4}$ failed to mount a $\mathrm{LTC}_{4}$ synthesizing response (Figure 1, right panel). In addition, eosinophil stimulation with $\mathrm{LTB}_{4}$ was also unable to trigger synthesis of other eicosanoids such as $\mathrm{PGE}_{2}$ or even the biogenesis of lipid bodies - organelles, which compartmentilize AA metabolism within eosinophils and other cell types, and that are promptly assembled under stimulation that leads to eicosanoid synthesis (Bozza et al., 1997b).

\section{PLATELET ACTIVATING FACTOR}

Human eosinophils are prominent among cell populations that respond to PAF stimulation displaying, besides chemotaxis, numerous PAF-driven functions, including migration-related activities such as adhesion and expression of cell surface molecules, as well as, secretory functions, including superoxide production and release of cationic granule proteins and stored cytokines (Wardlaw etal., 1986; Kroegel et al., 1989; Zoratti et al., 1991; Takizawa etal., 2002; Dyer etal., 2010). Equally important is the notion that although only one PAFR has been identified, PAF-driven signaling has emerged as a complex phenomenon, displaying differences between eosinophil chemotactic versus secretory functions and therefore suggesting the existence of yet non-characterized receptors (Kato et al., 2004).

It is noteworthy that PAF was the first stimulus to have its lipid body-dependent mechanism of eliciting LTC $_{4}$ synthesis characterized. PAF, acting via its G-protein-linked receptor induces lipid body formation via a downstream signaling involving $\mathrm{PKC}$ and phospholipase C (PLC) activation (Figure 1, right panel; Bozza etal., 1996, 1997a, 1998). Even more relevant to PAF ability of inducing $\mathrm{LTC}_{4}$ synthesis, it was the demonstration that the major enzymes involved in the enzymatic conversion of AA into $\mathrm{LTC}_{4}$, 5-LO, and $\mathrm{LTC}_{4}$ synthase, were found compartmentalized within PAF-induced newly assembled eosinophil lipid bodies (Bozza et al., 1997a, 1998) and that these enzymes were functional and producing $\mathrm{LTC}_{4}$ within theses organelles (Bandeira-Melo et al., 2001).

\section{CYSTEINYL LEUKOTRIENES}

Cysteinyl leukotrienes exert their actions by engaging specific receptors. Al least two cysLT receptors (cysLTRs) have been cloned and characterized, the CysLT1 and CysLT2 receptors (Lynch et al., 1999; Sarau et al., 1999; Heise et al., 2000; Nothacker et al., 2000). These receptors can be distinguished with pharmacologic inhibitors and by their differing ligand-binding affinities. In addition, various findings suggest the existence of other, not yet cloned, cysLTR (Panettieri et al., 1998; Ravasi et al., 2000; Mellor et al., 2002).

Inasmuch as eosinophils express functional receptors for cysteinyl LTs, it has been investigated their potential role as stimuli of eosinophil activation. Indeed, a series of reports showed cysteinyl LTs ability to affect various eosinophil responses. For instance, 
cysteinyl LTs promote CysLT ${ }_{1}$-dependent calcium influx on HL60 (Thivierge et al., 2000; Murray et al., 2003b). We have also shown that $\mathrm{LTC}_{4}, \mathrm{LTD}_{4}$, and $\mathrm{LTE}_{4}$ induced a dose- and timedependent, vesicular transport-mediated release of pre-formed IL-4 from eosinophils derived in vitro from human cord blood progenitors (Bandeira-Melo et al., 2002a). Although some controversy exist (Murray et al., 2003b), cysteinyl LTs also appear to be able to induce in vitro survival of human eosinophils by activation of CysLT 1 receptors (Lee et al., 2000; Becler et al., 2002). It is noteworthy that in addition to their recognized activities as paracrine mediators, eicosanoids like cysteinyl LTs are now also recognized to display autocrine effects. Indeed, eosinophil-derived cysteinyl LTs exert autocrine effects to enhance eosinophil survival triggered by GM-CSF, as well as, mast cell- and lymphocytederived molecules (Lee et al., 2000). Moreover, the capacity of eotaxin to stimulate the vesicular transport-mediated release of pre-formed IL-4 from human eosinophil granules is dependent of an endogenous $\mathrm{LTC}_{4}$, formed at eosinophil lipid bodies, that acting as an intracrine signaling molecule regulates this CCR3elicited IL-4 release (Bandeira-Melo et al., 2002c). Thus, LTC $_{4}$ may act intracellularly as intracrine signal transducing mediators. Indeed, cysteinyl LTs-responsive receptors have been identified on the membranes of intracellular eosinophil granule organelles and appear to function mediating cysteinyl LTs-stimulated secretion from within eosinophil granules, including those granules found extracellularly (Neves et al., 2010). On the other hand ans as illustrated in Figure 1 (right panel), specifically regarding the ability of activating LTC $_{4}$ synthesis, none endogenous or exogenous cysteinyl LTs displayed the ability to trigger lipid body biogenesis or to elicit their own synthesis (Bandeira-Melo et al., 2002c).

\section{PROSTAGLANDIN $\mathrm{D}_{2}$}

Besides migration-related cell functions, it is now wellcharacterized that $\mathrm{PGD}_{2}$ is a potent inducer of eosinophil activation, being capable of promoting eosinophil secretory activity. For instance, $\mathrm{PGD}_{2}$ is capable of triggering eosinophil degranulation, which appears to be induced by the selective $\mathrm{DP}_{2}$ agonist but not by selective $\mathrm{DP}_{1}$ agonist, suggesting for $\mathrm{DP}_{2}$ a role in modulating, not only eosinophil migration, but also activation (Gervais etal., 2001). We have also shown that, in addition to its eosinophilotactic activity, $\mathrm{PGD}_{2}$ controls allergy-relevant eosinophil activation parameter: the increased $\mathrm{LTC}_{4}$-synthesizing capacity of these cells (Mesquita-Santos et al., 2006). Indeed, other eosinophilotactic mediators, including eotaxin, RANTES, and PAF are capable of triggering $\mathrm{LTC}_{4}$ synthesis within eosinophils through activation of their cognate Gai-coupled chemotactic receptors (e.g., CCR3; Bozza et al., 1996; Bandeira-Melo et al., 2001). However, $\mathrm{PGD}_{2}$-induced $\mathrm{LTC}_{4}$ synthesis, surprisingly and distinctly from other parameters of eosinophil activation evoked by $\mathrm{PGD}_{2}$, was not mediated by the stimulatory activation of $\mathrm{DP}_{2}$ receptors while being counter-balanced by a parallel inhibitory cAMP-dependent $\mathrm{DP}_{1}$ receptor activation. On contrary, it does depend on a novel kind of interaction between the $\mathrm{PGD}_{2}$ receptor types expressed on eosinophils (Figure 1, right panel). Eosinophil $\mathrm{LTC}_{4}$ synthesis triggered by $\mathrm{PGD}_{2}$ is controlled by complementary stimulatory events between $\mathrm{DP}_{1}$ receptor-activated lipid bodies and concurrent $\mathrm{DP}_{2}$ receptor signaling (Mesquita-Santos et al., 2011). While $\mathrm{PGD}_{2}$ emerges as a potent inflammatory mediator of allergic disorders and as an interesting therapeutic target, because of the mandatory dual activation of $\mathrm{DP}_{1}$ and $\mathrm{DP}_{2}$ receptors for increasing eosinophil $\mathrm{LTC}_{4}$ synthesis, either $\mathrm{DP}_{1}$ or $\mathrm{DP}_{2}$ receptor antagonists might be highly effective candidates as anti-allergic tools to control cysteinyl LTs production regulated by the activation of eosinophils at sites of allergic reactions. On the top of that, we had recently also found out that upon proper stimulation, both human and mouse eosinophils can produce significant amounts of biologically relevant $\mathrm{PGD}_{2}$ (Luna-Gomes et al., 2011). $\mathrm{PGD}_{2}$ intracellular synthesis within eosinophils led to $\mathrm{PGD}_{2}$ receptor-mediated paracrine/autocrine functions, contributing to eosinophil activation. Indeed, eosinophil-derived $\mathrm{PGD}_{2}$ appears to be capable of regulating both eosinophil motility, as well as, lipid body-driven LTC $_{4}$ synthesis within eosinophils stimulated with eotaxin, for instance.

\section{FINAL REMARKS}

It is clear that several relevant aspects of lipid mediator impact on eosinophil biology need to be further characterized, however knowledge on this subject had evolved dramatically in the last decades. Among the most significant advances on eosinophil/lipid mediator axis are: (i) the recognition that eosinophils express the multitude of lipid mediator receptors on their surface, even those receptor pairs with apparently opposing functional outcomes under activation; (ii) the appreciation that not only eosinophil migration is elicited by lipid mediators, but maybe even more therapeutically relevant, activation of eosinophil secretory functions; and (iii) the acknowledgment of a wide-ranging induced signaling and consequently functional potentiality for lipid mediator-stimulated eosinophils that have still unpredicted impact to surrounding eosinophilic immuno-pathologies.

Still of special interest for eosinophil biology with roles in maximizing eosinophil functional potentialities is the rising observations unraveling intricate interactions between lipid mediators (such as $\mathrm{LTC}_{4}$ and $\mathrm{PGD}_{2}$ ) and eosinophil-relevant chemokines and other proteic stimuli. Possibly the most illustrative example of such cross-talking is eosinophil stimulation by eotaxin, a key mediator in the development of allergic eosinophilia that is known by its potent eosinophilotactic activity and has emerged as a potent mediator of eosinophil activation. Among a number of data on eotaxin/AA metabolites interdependency, some hallmarks are the sequencial events: (i) eotaxin particular ability to acutely enhance $\mathrm{PGD}_{2}$ synthesis by eosinophils by stimulating CCR3 receptors (Mesquita-Santos et al., 2006; Luna-Gomes et al., 2011); (ii) the subsequent autocrine/paracrine induction of lipid body biogenesis and lipid body-located LTC $_{4}$ synthesis by eosinophil-derived $\mathrm{PGD}_{2}$ (Luna-Gomes et al., 2011); followed by (iii) LTC $_{4}$-driven intracrine induction of piecemeal degranulation of granule-stored IL-4 by eotaxin-stimulated eosinophils (Bandeira-Melo et al., 2002c). Nevertheless, eotaxin is not the only example of such lipid/protein cooperation. It is still noteworthy that cell types other than eosinophils also undergo such lipid mediator/protein mediator cross-talking in regulating cell activation. Either infection-elicited or oxLDL-driven MCP1, for instance, 
besides its known CCR2-driven chemotactic function, appear as a key activator of lipid body biogenic and leukotriene synthesizing machineries within macrophagic cells (Pacheco et al., 2007; Silva et al., 2009). Once more specifically regarding eosinophils, synergistic effects on eliciting eosinophil chemotaxis have been also described between $\mathrm{PGD}_{2}$ and at least the cytokines IFN- $\gamma$ and TNF- $\alpha$ (El-Shazly et al., 2011), as well as, between $\mathrm{DP}_{2}$ activation

\section{REFERENCES}

Bandeira-Melo, C., Hall, J. C., Penrose, J. F., and Weller, P. F. (2002a). Cysteinyl leukotrienes induce IL4 release from cord blood-derived human eosinophils. J. Allergy Clin. Immunol. 109, 975-979.

Bandeira-Melo, C., Sugiyama, K., Woods, L. J., Phoofolo, M., Center, D. M., Cruikshank, W. W., et al. (2002b). IL-16 promotes leukotriene $\mathrm{C}(4)$ and IL-4 release from human eosinophils via CD4- and autocrine CCR3-chemokine-mediated signaling. J. Immunol. 168, 47564763.

Bandeira-Melo, C., Woods, L. J., Phoofolo, M., and Weller, P. F. (2002c). Intracrine cysteinyl leukotriene receptor-mediated signaling of eosinophil vesicular transport-mediated interleukin4 secretion. J. Exp. Med. 196, 841-850.

Bandeira-Melo, C., Phoofolo, M., and Weller, P. F. (2001). Extranuclear lipid bodies, elicited by CCR3-mediated signaling pathways, are the sites of chemokine-enhanced leukotriene C4 production in eosinophils and basophils. J. Biol. Chem. 276, 22779 22787.

Bandeira-Melo, C., and Weller, P. F. (2003). Eosinophils and cysteinyl leukotrienes. Prostaglandins Leukot. Essent. Fatty Acids 69, 135-143.

Becler, K., Håkansson, L., and Rak, S. (2002). Treatment of asthmatic patients with a cysteinyl leukotriene receptor-1 antagonist montelukast (Singulair), decreases the eosinophil survival-enhancing activity produced by peripheral blood mononuclear leukocytes in vitro. Allergy 57, 10211028.

Bozza, P. T., Payne, J. L., Goulet, J. L., and Weller, P. F. (1996). Mechanisms of platelet-activating factor-induced lipid body formation: requisite roles for 5-lipoxygenase and de novo protein synthesis in the compartmentalization of neutrophil lipids. J. Exp. Med. 183, 1515-1525.

Bozza, P. T., Yu, W., Cassara, J., and Weller, P. F. (1998). Pathways for eosinophil lipid body induction: differing signal transduction in cells from normal and hypereosinophilic subjects. J. Leukoc. Biol. 64, 563-569.
Bozza, P. T., Yu, W., Penrose, J. F., Morgan, E. S., Dvorak, A. M., and Weller, P. F. (1997a). Eosinophil lipid bodies: specific, inducible intracellular sites for enhanced eicosanoid formation. J. Exp. Med. 186, 909-920.

Bozza, P. T., Yu, W., and Weller, P. F. (1997b). Mechanisms of formation and function of eosinophil lipid bodies: inducible intracellular sites involved in arachidonic acid metabolism. Mem. Inst. Oswaldo Cruz 92(Suppl. 2), 135-140.

Chan, C. C., McKee, K., Tagari, P., Chee, P., and Ford-Hutchinson, A. (1990) Eosinophil-eicosanoid interactions: inhibition of eosinophil chemotaxis in vivo by a LTD4-receptor antagonist. Eur. J. Pharmacol. 191 273-280.

Dent, G., Munoz, N. M., Zhu, X. Rühlmann, E., Magnussen, H., Leff, A. R., et al. (2000). Involvement of protein tyrosine kinases in activation of human eosinophils by plateletactivating factor. Immunology 100 231-237.

Dyer, K. D., Percopo, C. M., Xie, Z., Yang, Z., Kim, J. D., Davoine, F., et al. (2010). Mouse and human eosinophils degranulate in response to platelet-activating factor (PAF) and lysoPAF via a PAF-receptorindependent mechanism: evidence for a novel receptor. J. Immunol. 184, 6327-6334.

El-Shazly, A. E., Begon, D. Y., Kustermans, G., Arafa, M., Dortu, E., Henket, M., et al. (2013). Novel Association between vasoactive intestinal peptide and CRTH2 receptor in recruiting eosinophils: a possible biochemical mechanism for allergic eosinophilic inflammation of the airways. J. Biol. Chem. 288, 1374 1384.

El-Shazly, A. E., Moonen, V., Mawet, M., Begon, D., Henket, M., Arafa M., etal. (2011). IFN- $\gamma$ and TNF- $\alpha$ potentiate prostaglandin D2-induced human eosinophil chemotaxis through up-regulation of CRTH2 surface receptor. Int. Immunopharmacol. $\quad 11, \quad 1864$ 1870.

Emery, D. L., Djokic, T. D., Graf, P. D., and Nadel, J. A. (1989). Prostaglandin D2 causes accumulation of eosinophils in the lumen of

and vasoactive intestinal peptide VIP (El-Shazly etal., 2013). Moreover, RANTES, IL-16 and MIF are also proteic mediators capable of activating eicosanoid synthesizing machinery within eosinophils culminating with the generation of $\mathrm{LTC}_{4}$ and $\mathrm{PGD}_{2}$, that in turn intracrinally or autocrinally mediate eosinophil secretory functions (Bandeira-Melo et al., 2002b,c; Vieira-de-Abreu et al., 2011).

the dog trachea. J. Appl. Physiol. 67, 959-962.

Faccioli, L. H., Nourshargh, S., Moqbel, R., Williams, F. M., Sehmi, R., Kay, A. B., et al. (1991). The accumulation of 111In-eosinophils induced by inflammatory mediators, in vivo. Immunology 73, 222-227.

Fregonese, L., Silvestri, M., Sabatini, F., and Rossi, G. A. (2002). Cysteinyl leukotrienes induce human eosinophil locomotion and adhesion molecule expression via a CysLT1 receptor-mediated mechanism. Clin. Exp. Allergy 32, 745-750.

Gervais, F. G., Cruz, R. P., Chateauneuf, A., Gale, S., Sawyer, N., Nantel, F., et al. (2001). Selective modulation of chemokinesis, degranulation, and apoptosis in eosinophils through the PGD2 receptors CRTH2 and DP. J. Allergy Clin. Immunol. 108, 982-988.

Grigg, J. (2012). The platelet activating factor receptor: a new anti-infective target in respiratory disease? Thorax 67, 840-841.

Heise, C. E., O’Dowd, B. F., Figueroa, D. J., Sawyer, N., Nguyen, T., Im, D. S., et al. (2000). Characterization of the human cysteinyl leukotriene 2 receptor. J. Biol. Chem. 275, 3053130536.

Huang, W. W., Garcia-Zepeda, E. A., Sauty, A., Oettgen, H. C., Rothenberg, M. E., and Luster, A. D. (1998). Molecular and biological characterization of the murine leukotriene B4 receptor expressed on eosinophils. $J$. Exp. Med. 188, 1063-1074.

Jacobsen, E. A., Helmers, R. A., Lee, J. J., and Lee, N. A. (2012). The expanding role(s) of eosinophils in health and disease. Blood 120, 3882-3890.

Kanwar, S., Johnston, B., and Kubes, P. (1995). Leukotriene C4/D4 induces P-selectin and sialyl Lewis(x)-dependent alterations in leukocyte kinetics in vivo. Circ. Res. 77, 879-887.

Kato, M., Kita, H., Tachibana, A., Hayashi, Y., Tsuchida, Y., and Kimura, H. (2004). Dual signaling and effector pathways mediate human eosinophil activation by platelet-activating factor. Int. Arch. Allergy Immunol. 134(Suppl. 1), 37-43.

Kawano, T., Matsuse, H., Kondo, Y., Machida, I., Saeki, S., Tomari, S., et al. (2003). Cysteinyl leukotrienes induce nuclear factor kappa b activation and RANTES production in a murine model of asthma. J. Allergy Clin. Immunol. 112, 369-374.

Kimani, G., Tonnesen, M. G., and Henson, P. M. (1988). Stimulation of eosinophil adherence to human vascular endothelial cells in vitro by platelet-activating factor. J. Immunol. 140, 3161-3166.

Klebanoff, S. J., Durack, D. T., Rosen, H., and Clark, R. A. (1977). Functional studies on human peritoneal eosinophils. Infect. Immun. 17, 167-173.

Kroegel, C., Yukawa, T., Dent, G., Venge, P., Chung, K. F., and Barnes, P. J. (1989). Stimulation of degranulation from human eosinophils by plateletactivating factor. J. Immunol. 142, 3518-3526.

Laitinen, L. A., Laitinen, A., Haahtela, T., Vilkka, V., Spur, B. W., and Lee, T. H. (1993). Leukotriene E4 and granulocytic infiltration into asthmatic airways. Lancet 341 , 989-990.

Lee, E., Robertson, T., Smith, J., and Kilfeather, S. (2000). Leukotriene receptor antagonists and synthesis inhibitors reverse survival in eosinophils of asthmatic individuals. Am. J. Respir. Crit. Care Med. 161, 1881-1886.

Lee, J. J., Jacobsen, E. A., Ochkur, S. I., McGarry, M. P., Condjella, R. M., Doyle, A. D., et al. (2012). Human versus mouse eosinophils: 'that which we call an eosinophil, by any other name would stain as red'. J. Allergy Clin. Immunol. 130, 572-584.

Lindsay, M. A., and Giembycz, M. A. (1997). Signal transduction and activation of the NADPH oxidase in eosinophils. Mem. Inst. Oswaldo Cruz 92(Suppl. 2), 115-123.

Lindsay, M. A., Haddad, E. B., Rousell, J., Teixeira, M. M., Hellewell, P. G., Barnes, P. J., et al. (1998a). Role of the mitogen-activated protein kinases and tyrosine kinases during leukotriene B4-induced eosinophil activation. J. Leukoc. Biol. 64, 555-562.

Lindsay, M. A., Perkins, R. S., Barnes, P. J., and Giembycz, M. A. (1998b). Leukotriene B4 activates the NADPH oxidase in eosinophils by a pertussis toxin-sensitive mechanism that is 
largely independent of arachidonic acid mobilization. J. Immunol. 160, 4526-4534.

Luna-Gomes, T., Magalhães, K. G., Mesquita-Santos, F. P., Bakker-Abreu, I., Samico, R. F., Molinaro, R., et al. (2011). Eosinophils as a novel cell source of prostaglandin D2: autocrine role in allergic inflammation. J. Immunol. 187, 65186526.

Lynch, K. R., O’Neill, G. P., Liu, Q., Im, D. S., Sawyer, N., Metters, K. M., et al. (1999). Characterization of the human cysteinyl leukotriene CysLT1 receptor. Nature 399, 789-793.

Martins, M. A., Silva, P. M., Faria Neto, H. C., Bozza, P. T., Dias, P. M., Lima, M. C., et al. (1989). Pharmacological modulation of Paf-induced rat pleurisy and its role in inflammation by zymosan. Br. J. Pharmacol. 96, 363-371.

Matsuoka, T., Hirata, M., Tanaka, H., Takahashi, Y., Murata, T., Kabashima, K., et al. (2000). Prostaglandin D2 as a mediator of allergic asthma. Science 287, 2013-2017.

Mellor, E. A., Austen, K. F., and Boyce, J. A. (2002). Cysteinyl leukotrienes and uridine diphosphate induce cytokine generation by human mast cells through an interleukin 4-regulated pathway that is inhibited by leukotriene receptor antagonists. J. Exp. Med. 195, 583-592.

Mesquita-Santos, F. P., Bakker-Abreu, I., Luna-Gomes, T., Bozza, P. T., Diaz, B. L., and Bandeira-Melo, C. (2011). Co-operative signalling through $\mathrm{DP}(1)$ and $\mathrm{DP}(2)$ prostanoid receptors is required to enhance leukotriene $\mathrm{C}(4)$ synthesis induced by prostaglandin $\mathrm{D}(2)$ in eosinophils. Br. J. Pharmacol. 162, 16741685.

Mesquita-Santos, F. P., Vieira-de-Abreu, A., Calheiros, A. S., Figueiredo, I. H., Castro-Faria-Neto, H. C., Weller, P. F., et al. (2006). Cutting edge: prostaglandin D2 enhances leukotriene $\mathrm{C} 4$ synthesis by eosinophils during allergic inflammation: synergistic in vivo role of endogenous eotaxin. J. Immunol. 176, 1326-1330.

Miike, S., Kurasawa, K., Saito, Y., and Iwamoto, I. (2000). Plateletactivating factor activates mitogenactivated protein kinases through the activation of phosphatidylinositol 3kinase and tyrosine kinase in human eosinophils. J. Leukoc. Biol. 67, 117-126.

Mishra, R. K., Scaife, J. E., Harb, Z., Gray, B. C., Djukanovic, R., and Dent, G. (2005). Differential dependence of eosinophil chemotactic responses on phosphoinositide 3-kinase (PI3K). Allergy 60, 1204-1207.

Monneret, G., Cossette, C., Gravel, S., Rokach, J., and Powell, W. S. (2003). 15R-methyl-prostaglandin D2 is a potent and selective CRTH2/DP2 receptor agonist in human eosinophils. J. Pharmacol. Exp. Ther. 304, 349-355.

Monneret, G., Gravel, S., Diamond, M., Rokach, J., and Powell, W. S. (2001). Prostaglandin D2 is a potent chemoattractant for human eosinophils that acts via a novel DP receptor. Blood 98, 1942-1948.

Murray, J., Ward, C., O'Flaherty, J. T., Dransfield, I., Haslett, C., Chilvers, E. R., et al. (2003a). Role of leukotrienes in the regulation of human granulocyte behaviour: dissociation between agonist-induced activation and retardation of apoptosis. Br. J. Pharmacol. 139, 388-398.

Murray, J., Ward, C., O'Flaherty, J. T., Dransfield, I., Haslett, C., Chilvers, E. R., et al. (2003b). Role of leukotrienes in the regulation of human granulocyte behaviour: dissociation between agonist-induced activation and retardation of apoptosis. Br. J. Pharmacol. 139, 388-398.

Neves, J. S., Radke, A. L., and Weller, P. F. (2010). Cysteinyl leukotrienes acting via granule membrane-expressed receptors elicit secretion from within cell-free human eosinophil granules. J. Allergy Clin. Immunol. 125, 477-482.

Nothacker, H. P., Wang, Z., Zhu, Y. Reinscheid, R. K., Lin, S. H., and Civelli, O. (2000). Molecular cloning and characterization of a second human cysteinyl leukotriene receptor: discovery of a subtype selective agonist. Mol. Pharmacol. 58, 16011608.

O'Driscoll, B. R., Cromwell, O., and Kay, A. B. (1984). Sputum leukotrienes in obstructive airways diseases. Clin. Exp. Immunol. 55, 397-404.

Pacheco, P., Vieira-de-Abreu, A., Gomes, R. N., Barbosa-Lima, G., Wermelinger, L. B., MayaMonteiro, C. M., et al. (2007). Monocyte chemoattractant protein1/CC chemokine ligand 2 controls microtubule-driven biogenesis and leukotriene B4-synthesizing function of macrophage lipid bodies elicited by innate immune response. J. Immunol. 179, 8500-8508.

Panettieri, R. A., Tan, E. M., Ciocca, V., Luttmann, M. A., Leonard, T. B., and Hay, D. W. (1998). Effects of LTD4 on human airway smooth muscle cell proliferation, matrix expression, and contraction
In vitro: differential sensitivity to cysteinyl leukotriene receptor antagonists. Am. J. Respir. Cell Mol. Biol. 19, 453-461.

Perkins, R. S., Lindsay, M. A., Barnes, P. J., and Giembycz, M. A. (1995). Early signalling events implicated in leukotriene B4-induced activation of the NADPH oxidase in eosinophils: role of $\mathrm{Ca} 2+$, protein kinase $\mathrm{C}$ and phospholipases C and D. Biochem. J. 310(Pt 3), 795-806.

Peters-Golden, M. (2008). Expanding roles for leukotrienes in airway inflammation. Curr. Allergy Asthma Rep. 8, 367-373.

Powell, W. S. (2003). A novel PGD(2) receptor expressed in eosinophils. Prostaglandins Leukot. Essent. Fatty Acids 69, 179-185.

Ravasi, S., Capra, V., Mezzetti, M., Nicosia, S., and Rovati, G. E. (2000). A kinetic binding study to evaluate the pharmacological profile of a specific leukotriene $\mathrm{C}(4)$ binding site not coupled to contraction in human lung parenchyma. Mol. Pharmacol. 57, 1182-1189.

Royer, J. F., Schratl, P., Carrillo, J. J. Jupp, R., Barker, J., Weyman-Jones, C., etal. (2008). A novel antagonist of prostaglandin D2 blocks the locomotion of eosinophils and basophils. Eur. J. Clin. Invest. 38, 663-671.

Saito, H., Morikawa, H., Howie, K., Crawford, L., Baatjes, A. J., Denburg, E., et al. (2004). Effects of a cysteinyl leukotriene receptor antagonist on eosinophil recruitment in experimental allergic rhinitis. Immunology 113, 246-252.

Sandig, H., Pease, J. E., and Sabroe, I. (2007). Contrary prostaglandins: the opposing roles of PGD2 and its metabolites in leukocyte function. $J$. Leukoc. Biol. 81, 372-382.

Sarau, H. M., Ames, R. S., Chambers, J., Ellis, C., Elshourbagy, N., Foley, J. J., et al. (1999). Identification, molecular cloning, expression, and characterization of a cysteinyl leukotriene receptor. Mol. Pharmacol. 56, 657-663.

Sawyer, N., Cauchon, E., Chateauneuf, A., Cruz, R. P. G., Nicholson, D. W., Metters, K. M., etal. (2002). Molecular pharmacology of the human prostaglandin D2 receptor, CRTH2. Br. J. Pharmacol. 137, 1163-1172.

Secor, W. E., Stewart, S. J., and Colley, D. G. (1990). Eosinophils and immune mechanisms. VI. The synergistic combination of granulocyte-macrophage colonystimulating factor and IL-5 accounts for eosinophil-stimulation promoter activity in Schistosoma mansoniinfected mice. J. Immunol. 144, 14841489.

Sedej, M., Schröder, R., Bell, K., Platzer, W., Vukoja, A., Kostenis, E., et al. (2012). D-type prostanoid receptor enhances the signaling of chemoattractant receptorhomologous molecule expressed on $\mathrm{T}(\mathrm{H}) 2$ cells. J. Allergy Clin. Immunol. 129, 492-500.

Shindo, K., Miyakawa, K., and Fukumura, M. (1993). Plasma levels of leukotriene B4 in asthmatic patients. Int. J. Tissue React. 15, 181-184.

Shiraishi, Y., Asano, K., Nakajima, T., Oguma, T., Suzuki, Y., Shiomi, T., et al. (2005). Prostaglandin D2induced eosinophilic airway inflammation is mediated by CRTH2 receptor. J. Pharmacol. Exp. Ther. 312, 954-960.

Silva, A. R., Pacheco, P., Vieira-deAbreu, A., Maya-Monteiro, C. M., D’Alegria, B., Magalhães, K. G., et al. (2009). Lipid bodies in oxidized LDL-induced foam cells are leukotriene-synthesizing organelles: a MCP-1/CCL2 regulated phenomenon. Biochim. Biophys. Acta 1791, 1066-1075.

Simson, L., and Foster, P. S. (2000). Chemokine and cytokine cooperativity: eosinophil migration in the asthmatic response. Immunol. Cell Biol. 78, 415-422.

Spada, C. S., Krauss, A. H., Nieves, A. L., and Woodward, D. F. (1997). Effects of leukotrienes B4 (LTB4) and D4 (LTD4) on motility of isolated normodense human eosinophils and neutrophils. Adv. Exp. Med. Biol. 400B, 699-706.

Spik, I., Brénuchon, C., Angéli, V., Staumont, D., Fleury, S., Capron, M., et al. (2005). Activation of the prostaglandin D2 receptor DP2/CRTH2 increases allergic inflammation in mouse. J. Immunol. 174, 3703-3708.

Tager, A. M., Dufour, J. H., Goodarzi, K., Bercury, S. D., von Andrian, U. H., and Luster, A. D. (2000). BLTR mediates leukotriene B(4)induced chemotaxis and adhesion and plays a dominant role in eosinophil accumulation in a murine model of peritonitis. J. Exp. Med. 192, 439-446.

Takizawa, T., Kato, M., Kimura, H., Suzuki, M., Tachibana, A., Obinata, H., et al. (2002). Inhibition of protein kinases $\mathrm{A}$ and $\mathrm{C}$ demonstrates dual modes of response in human eosinophils stimulated with platelet-activating factor. J. Allergy Clin. Immunol. 110, 241-248. 
Teixeira, M. M., Lindsay, M. A., Giembycz, M. A., and Hellewell, P. G. (1999). Role of arachidonic acid in leukotriene $\mathrm{B}(4)$-induced guineapig eosinophil homotypic aggregation. Eur. J. Pharmacol. 384, 183-190.

Thivierge, M., Doty, M., Johnson, J., Stanková, J., and Rola-Pleszczynski, M. (2000). IL-5 up-regulates cysteinyl leukotriene 1 receptor expression in HL-60 cells differentiated into eosinophils. J. Immunol. 165, 52215226.

Toda, A., Yokomizo, T., and Shimizu, T. (2002). Leukotriene B4 receptors. Prostaglandins Other Lipid Mediat. 68-69, 575-585.

Ulven, T., and Kostenis, E. (2006). Targeting the prostaglandin $\mathrm{D} 2$ receptors DP and CRTH2 for treatment of inflammation. Curr. Top. Med. Chem. 6, 1427-1444.

Vieira-de-Abreu, A., Calheiros, A. S., Mesquita-Santos, F. P., Magalhães, E. S., Mourão-Sá, D., Castro-FariaNeto, H. C., et al. (2011). Crosstalk between macrophage migration inhibitory factor and eotaxin in allergic eosinophil activation forms leukotriene C4-synthesizing lipid bodies. Am. J. Respir. Cell Mol. Biol. 44, 509-516.

Wang, J. M., Rambaldi, A., Biondi, A., Chen, Z. G., Sanderson, C. J., and Mantovani, A. (1989). Recombinant human interleukin 5 is a selective eosinophil chemoattractant. Eur. J. Immunol. 19, 701-705.

Wardlaw, A. J., Hay, H., Cromwell, O. Collins, J. V., and Kay, A. B. (1989). Leukotrienes, LTC4 and LTB4, in bronchoalveolar lavage in bronchial asthma and other respiratory diseases. J. Allergy Clin. Immunol. 84, $19-26$.

Wardlaw, A. J., Moqbel, R., Cromwell, O., and Kay, A. B. (1986). Plateletactivating factor. A potent chemotactic and chemokinetic factor for human eosinophils. J. Clin. Invest. 78, 1701-1706.

Weller, P. F., Lee, C. W., Foster, D. W., Corey, E. J., Austen, K. F., and Lewis, R. A. (1983). Generation and metabolism of 5-lipoxygenase pathway leukotrienes by human eosinophils: predominant production of leukotriene C4. Proc. Natl. Acad. Sci. U.S.A. 80, 76267630.

Xue, L., Gyles, S. L., Barrow, A., and Pettipher, R. (2007). Inhibition of PI3K and calcineurin suppresses chemoattractant receptor-homologous molecule expressed on Th2 cells (CRTH2)-dependent responses of Th2 lymphocytes to prostaglandin D(2). Biochem. Pharmacol. 73, 843-853.

Yokomizo, T. (2011). Leukotriene B4 receptors: novel roles in immunological regulations. Adv. Enzyme Regul. 51, 59-64.

Zoratti, E. M., Sedgwick, J. B., Vrtis, R. R., and Busse, W. W. (1991). The effect of platelet-activating factor on the generation of superoxide anion in human eosinophils and neutrophils. J. Allergy Clin. Immunol. 88, 749-758.

Conflict of Interest Statement: The authors declare that the research was conducted in the absence of any commercial or financial relationships that could be construed as a potential conflict of interest.

Received: 08 February 2013; accepted: 23 February 2013; published online: 22 March 2013.

Citation: Luna-Gomes T, Bozza PT and Bandeira-Melo C (2013) Eosinophil recruitment and activation: the role of lipid mediators. Front. Pharmacol. 4:27. doi: 10.3389/fphar.2013.00027

This article was submitted to Frontiers in Experimental Pharmacology and Drug Discovery, a specialty of Frontiers in Pharmacology.

Copyright (c) 2013 Luna-Gomes, Bozza and Bandeira-Melo. This is an openaccess article distributed under the terms of the Creative Commons Attribution License, which permits use, distribution and reproduction in other forums, provided the original authors and source are credited and subject to any copyright notices concerning any third-party graphics etc. 